\title{
Recommendations of Russian Nutritionalists During the Covid-19 Era
}

ISSN: 2640-9208

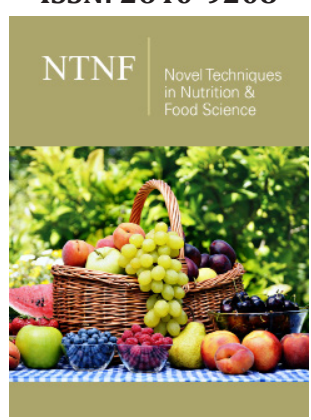

*Corresponding author: Irina Polyanskaya, Department of Hygienic Engineering and Design, Russia

Submission: 眥January 18, 2021

Published: 㭗April 07, 2021

Volume 5 - Issue 5

How to cite this article: Irina Polyanskaya Recommendations of Russian Nutritionalists During the Covid-19 Era. Nov Tech Nutri Food Sci. 5(5). NTNF. 000622. 2021. DOI: $10.31031 /$ NTNF.2021.05.000622

Copyright@ Irina Polyanskaya. This article is distributed under the terms of the Creative Commons Attribution 4.0 International License, which permits unrestricted use and redistribution provided that the original author and source are credited.
Irina Polyanskaya*

Department of Hygienic Engineering and Design, Russia

\section{Opinion}

Thank God, not the IXX century, information is available on the Internet, including from official sources, there is a lot of this information, but sometimes, when "time is gold", which in our era is marked as Alpha, in order to have time to save the situation before reaching Omega, we prepared recommendations in thesis form: For nutritional support in order to prevent all people under constant stress associated with the risk of infection, indirectly affecting the immune system, garlic, ginger, berries containing useful biologically active substances are recommended to increase the adaptive potential of the body, but it is noted that their preventive properties against COVID-19 infection have no evidence base. In general, a fullfledged, varied diet is needed, composed of traditional products, but with a slightly reduced calorie content, if physical activity is reduced due to quarantine.

Reducing calories is achieved through the use of foods of "high nutritional density", and it is recommended to maintain physical activity even in conditions of self-isolation, which can help, in particular, Internet fitness. Drinking regime includes 1 liter for children, 2 liters for adults, water including drinks. Products with "high nutritional density" include functional foods, biologically active additives, specialized products that allow you to supply the body with the optimal amount of complete protein, omega- 3 fatty acids, vitamins, bioelements, without exceeding the daily calorie content and excluding the feeling of hunger. Limit salt, sugar, animal fats, trans fats and foods containing them. It is especially important to increase the adaptive potential of the optimal intake of high-quality protein, for example, a product from whey, vitamins A, E, D, C, bioelements zinc and selenium.

With an acute infectious process with fever, patients can lose up to 6kg of muscle tissue with a loss of protein up to $200 \mathrm{~g}$ per day. At the same time, along with negative nitrogen metabolism, polyhypovitaminosis is observed, a violation of water-electrolytic metabolism, and anemia may develop. In this case, diets reinforced with the aforementioned specialized foods are required. The patient should not be allowed to starve and then overeat, gaining excess weight. Given the state of the nervous system, strong coffee, tea, very strong broth is limited. Drinks that reduce stress are desirable, for example with motherwort, valerian, mint. Russian nutritionist M.I. Pevsner recommended that in acute infectious diseases patients who tolerate alcohol well, give 30-40g of cognac, adding it to tea, or, equivalently, natural wines mixed with water.

In case of infectious-toxic shock in intensive care units - artificial balanced nutrition to stabilize the nutritional status. In Russia, specialized food products "Diso ${ }^{\circledR}$ " "Nutrinor Ca" have been developed and their effectiveness has been proven in enhancing anti-inflammatory therapy in diseases with similar symptomatic fever, in particular tuberculosis. Prepared based on the materials of the Russian journal "Practical Dietetics": Irina Polyanskaya, Vologda Dairy Academy, Vologda, Russia.

For possible submissions Click below: 